\title{
SITUACIÓN Y AVANCES TECNOLOGICOS EN LA PRODUCCIÓN BANANERA MUNDIAL ${ }^{1}$
}

\author{
MOISÉS SOTO²
}

RESUMEN: El consumo de banano como fruta fresca, supera a todas las demás frutas,solo superado por el consumo de cítricos industriales. El grupo Cavendish es el de mayor produccion en el mundo, com um $47 \%$, principalmente de los clones Gran Enano(Nanica) y Valery(Nanicao). El Gros Michel representa en el mundo $12 \%$ de la producción, los plátanos de consumo cocido, grupo $\mathrm{AAB}$ un $17 \%$, mientras que los plátanos de tierras altas, conocidos como dulces, cultivados em las regiones tropicales como en el sur de Brasil, norte de Argentina, Islas Canárias y tierras altas de Filipinas han mostrado una gran aceptación. Es el grupo de Prata'. Las importaciones de banano em 2009 fueran de 14,5 miliones de ton, por Europa, EUA-Canada, Japon y otros países. Los principales países exportadores Equador, Filipinas, Costa Rica y otros.La banana orgânica tiene los mejores precios.

\section{WORLD SITUATION AND ADVANCES OF BANANA PRODUCTION AND TECHNOLOGY}

\begin{abstract}
The banana is the most consumed fruit at the world only surpassed by processed citrus. The most important banana types are the Cavendish group with $47 \%$, Prata types and others,with $24 \%$ and types for cooking,with $17 \%$. The group Gros Michael is $12 \%$. India is the biggest producer, with $19 \%$ of the total, followed by Brazil with $15 \%$, Equador with $12 \%$ and others with less than $10 \%$. In 2009 the banana importations were about 14,5 million tons, mainly by Europe Union, USA-Canada, Japan and others with less than one million tons each one. In 1,999 the banana importations were about 12 million tons. Equador is the most important exporting country with 4,7 million tons, followed by Phillipines, Costa Rica, Colômbia, Guatemala, Honduras and Panama. Prices variation were observed during the last years for banana market around the world, but the market is mantained stable and the organic banana with higher prices.
\end{abstract}

Index terms: world production, exportation, technology.

\section{SITUACIÓN ACTUAL Y PERSPECTIVAS DE LA PRODUCCIÓN BANANERA MUNDIAL}

\section{Consumo de bananos y otras frutas frescas}

El consumo de banano como fruta fresca en el mundo, supera a todas las demás frutas, incluyendo las manzanas, y solo es superado por el consumo de cítricos industriales.

\section{Producción mundial de musas}

Dentro del género musa, el Sub Grupo "Cavendish", es el de mayor producción en el mundo, con un 47\%, principalmente de los clones "Gran Enano" (Nanica) y "Valery" (Nanicao).

El "Gros Michel" y otros bananos postre como el Lady's Finger, representan un 12\% de la producción mundial, pero existe una tendencia a elevar el consumo del "Gros Michel" por su alta calidad en sabor,y fácil manejo pos cosecha.

Los plátanos de consumo cocido, grupo $\mathrm{AAB}$, representan un $17 \%$, mientras que los bananos de tierras altas, conocidos como "dulces"(Switer), que se cultivan también en condiciones sub tropicales, en el Sur de Brasil, Norte de Argentina, Islas Canarias, y tierras altas de Filipinas, han mostrado una gran aceptación por algunos mercados, como el japonés, por su sabor dulce.

A este grupo, también pertenecen los bananos de sabor agridulce, conocidos como "Prata", de gran consumo en Brasil, así como otros bananos de cocción de los grupos AAB,ABB y BBB. La producción mundial de estos bananos representa un $24 \%$.(Gráfico $\mathrm{N}^{\circ} 1$ )

\section{Producción de musas por continente}

Analizando la producción de musas por

${ }^{1}$ Palestra Sinfruit 102 - Simpósio Internacional de Fruticultura - Avanços na Fruticultura (17 a 21 Outubro)

${ }^{2}$ Universidad EARTH Universidad de Costa Rica. E-mail: piacostarica@gmail.com 
continente, se encuentra que los plátanos $\mathrm{AAB}$, de consumo cocido, se producen mayoritariamente en África, seguido por América Latina y el Caribe. Los bananos de tierras altas y otros $\mathrm{ABB}$, se producen en Asia, África y algo en América Latina.

EL Sub Grupo "Cavendish", se produce en mayor cantidad en América Latina y el Caribe, seguido de Asia (Filipinas), África (Camerún y Costa de Marfil), y Europa (Islas Canarias)

\section{Producción mundial de banano por países}

El país de mayor producción de banano del mundo, es India con un 19\%; seguido de Brasil con $15 \%$, y de Ecuador, con $12 \%$. China produce un $10 \%$, u y otros países como Colombia, Costa Rica, Filipinas y México, producen entre 6 y 4\%, seguido de un grupo grande de países, que con menos del 3\% individual, producen un $36 \%$ del total

\section{Exportaciones mundiales por países}

Las exportaciones mundiales de banano para el año 2008, fueron de 802,9 millones de cajas de $18,14 \mathrm{kgr}$, donde el mayor exportador es Ecuador con 260 millones, seguido por Filipinas y Costa Rica, con algo más de 100 millones. Colombia con casi 100 millones, ocupa la $4^{\circ}$ posición, seguido de Guatemala, que ha crecido mucho en los últimos años, con 74,5 millones. Le siguen Honduras, con 33,4 millones y Panamá con 20.

En áfrica, Camerún y Costa de Marfil, con 15,4 y 14,5 millones, son los mayores exportadores del continente.

No se incluyen en este cuadro, las exportaciones de los territorios de Ultramar de Europa (Islas Canarias, Guadalupe y Martinica), por considerarse producción propia de España y Francia, Grecia , Chipre y Portugal, por un total de 31, 2 millones de cajas, para el año 2008.

\section{Variación de oferta mundial, crecimiento por países y provecciones}

Si se analiza la variación de la oferta mundial, para los principales países exportadores y el resto del mundo, entre 1983 y el 2008, se encuentra:

Que la oferta mundial pasó de 5,8 millones de toneladas ,(322,2 millones de cajas de 18,14 kgrs) en el período 1983-85, hasta 10,7 millones de tonelada (588 millones de cajas), en el período 93-95, con crecimiento anual del $6,26 \%$, donde el país que mas creció fue Guatemala, con un 101,7 \%, seguido por Ecuador, con un $12,44 \%$, Costa Rica, con 7,89\%, y Colombia con $5,83 \%$.El resto del mundo apenas creció un 3,50\%.

Del período 93-95, al 2005, se creció de 10,7 millones de toneladas, a 13,3 millones de toneladas (731 millones de cajas), con una tasa de crecimiento anual del 2,24\%, donde todos los países crecieron poco, con excepción de Guatemala, que creció un $77,79 \%$.

Entre el período 2005 al 2008, se creció en 1,3 millones de toneladas (71,5 millones de cajas), con crecimiento anual del $3,27 \%$, donde la mayoría de los países crecieron al redor del promedio, y Guatemala, con 9,8\%, disminuyó el ritmo de crecimiento anterior.

Un crecimiento de la oferta del 3,27\% anual, asimilado por los mercados, parece ser una buena señal de crecimiento del consumo.

\section{Exportaciones mundiales de banano orgánico}

América Latina es el único exportador de banano orgánico, y las exportaciones totales para el año 2009, fueron de 24, 2 millones, que representan un $3 \%$ de las exportaciones totales de banano convencional.

El mayor exportador es Ecuador, con 9,9 millones de cajas de $18,14 \mathrm{kgr}$, que se producen en 10.500 hectáreas de cultivo. El segundo exportador es Republica Dominicana, con 5,5 millones de cajas, en 5.100 hectáreas. Perú, aunque recientemente ha entrado en el mercado, ya exporta 4,1 millones de cajas, en 5.250 hectáreas, ubicadas en la zona desértica de Piura, en su mayoría. Colombia, con 3,2 millones de cajas, requiere de 2250 hectáreas, pero problemas de calidad, han hecho reducir sus exportaciones recientemente

Para la producción de las 24,2 millones de cajas, se necesitan 23.750 hectáreas de cultivo, lo que muestra una productividad muy baja de 1019 cajas por hectárea por año, si se compara con las 2400 cajas que se producen en promedio, en Costa Rica de banano convencional.

Algunos proyectos de cultivo orgánico en Ecuador, con altas tecnologías de producción, alcanzan productividades de 2500 cajas por hectárea por año, de un producto de muy buena calidad (M,Soto,2010)

Las exportaciones de banano orgánico, se iniciaron en Honduras en 1997, y el crecimiento ha sido exponencial, con la entrada en el mercado de Republica Dominicana, Ecuador, Perú y Colombia. Es importante tener en consideración, para cualquier crecimiento, que este mercado es del $3 \%$ del mercado mundial, 24 millones de cajas, y que con pequeñas cantidades de sobre oferta sobre la demanda, los 
precios se caen abruptamente, como sucedió en el año 2009, con la entrada de Colombia al mercado.

\section{Importación mundial de banano}

Según la sección de estadísticas de CORBANA, Costa Rica, las importaciones de banano de la Unión Europea, en el 2008, fue de 4,8 millones de toneladas (266,7 millones de cajas de 18,14 kgrs), con una participación en el mercado del $33,2 \%$, y un incremento del 3,7\% sobre el 2007; para Estados Unidos y Canadá, fue de 4,7 millones de toneladas (260,0 millones de cajas), una participación de $32,4 \%$, manteniendo los mismos volúmenes, que el 2007; para Asia, fue de 2,3 millones de toneladas( 127,9 millones de cajas), con una participación de $15,9 \%$ del mercado, y un crecimiento del $14,6 \%$ sobre el 2007.

Los volúmenes de importación para el Resto de Europa, fueron de 1,6 millones de toneladas ( 87,4 millones de cajas), una participación en el mercado del $10,9 \%$, con un crecimiento del $1,8 \%$ con respecto al 2007.América Latina con 0,8 millones de toneladas ( 45,3 millones de cajas), y una participación del mercado del $5,6 \%$, con muy poco crecimiento con respecto al 2007.

África y el resto del mundo, con importaciones de 0,2 y0,08 millones de toneladas ( 11,4 y 4,4 millones de cajas, tienen una participación que entre las 2 llegan apenas al $2 \%$, con poco crecimiento desde el 2007.

Las importaciones de banano han crecido desde 688,4 millones de cajas en el 2005, hasta 800 millones de cajas en el 2008 (CUADRO N ${ }^{\circ}$ ).

Las mayores importaciones las hacen los países desarrollados, con 655,4 de cajas, de las cuales la Unión Europea 27, es el mayor importador, con 267 millones, seguido por Estados Unidos y Canadá, con 216,2 millones. Las Repúblicas EX USSR, con 76, 7 millones, son importadores importantes, sobre todo la Federación Rusa.

Japón, con importaciones de 65,8 millones, es importante, lo mismo que Lejano Oeste, con China y República de Corea, que importan 43,3 millones de cajas. América Latina importa 34,3 millones de cajas, y los principales importadores son Argentina, Chile, Uruguay, y el Salvador.

Otros de Europa, importan 29,6 millones de cajas.

\section{Variación de la demanda mundial y provección}

Al analizar la variación de la demanda mundial de banano, entre el año 1983 y el 2008, se observa, (CUADRO N 6).

Que el crecimiento de la demanda entre el periodo 1983-85, y el 1993-95, fue de 4,3 millones de toneladas (239,3 millones de cajas de 18,14 kgrs), que represento un crecimiento del 5,62\% anual. El mayor crecimiento de la demanda lo mostró Otros Europa, con un $24,70 \%$ En ese mismo período, la oferta (cuadro $\mathrm{N}^{\circ} 2$ ), pasó de de 5,8 millones de toneladas (322,2 millones de cajas), a 10,7 millones de toneladas (591,5 millones de cajas), con un crecimiento anual del $6,26 \%$, por lo que la oferta fue superior a la demanda, y los precios se mantuvieron comprimidos.

En el período 1993-95 al 2005, la demanda creció hasta 13 millones de toneladas ( 715 millones de cajas), con un crecimiento anual del 1,94\%, donde todos los países importadores crecieron muy poco, y el crecimiento en el resto del mundo fue negativo. En ese mismo período, la oferta fue de13,3 millones de toneladas (731,2 millones de cajas), apenas ligeramente superior a la demanda, lo que permitió un mercado balanceado, con precios con tendencia hacia el alza.

De los años 2005 al 2008, la demanda se incrementó hasta14,5 millones de toneladas ( 800 millones de cajas), y un 4,03\% anual, con incrementos muy notorios de la Unión Europea 27 y otros Europa, así como un crecimiento moderado en le resto del mundo. Si se compara la demanda de estos años con la oferta respectiva (CUADRO N ${ }^{\circ}$ ), se encuentra que la oferta fue de 14,6 millones de toneladas (802,1 millones de cajas), prácticamente igual a la demanda, y es por ello que en ese período el mercado se mantuvo balanceado, sin alti bajos, y con precios altos y estables.

Es indudable que la oferta se a estabilizado, tratando de mantenerse muy cerca de la demanda, ello como consecuencia, de que algunos países productores tradicionales del mercado bananero del mundo, por diferentes motivos, han reducido sus áreas de cultivo, y otros que en el pasado hacían grandes siembras cuando los precios estaban buenos, sus gobiernos han legislado para evitar lo sobre oferta.

Es indudable que los cambios en el mercadeo sucedidos hace al redor de 10 años, dividiendo la oferta en pre contratada y "spot", y al ser la fruta "spot" la menor parte del mercado, donde se ubican los países menos ordenados en la oferta, hace que cualquier sobre oferta, golpe más a esos países, que a los que venden en pre contrato, provocando crisis ocasionales en los productores, por lo que los gobiernos se han visto obligados a tomar cartas e el asunto, y legislar al respecto.

Con respecto al banano orgánico, la demanda 
estará entre un 3 al 5\% de la demanda total de banano, por lo que debe de fluctuar en los próximos años entre 25 y 40 millones de cajas al año, con un área sembrada de 2500 a 4000 hectáreas. Las condiciones ecológicas apropiadas para este cultivo, son difíciles de encontrar en el mundo, por lo que no es posible un crecimiento desmedido, a la vez, que algunas producciones establecidas en este momento, dejarán de hacerlo, por la alta tecnología requerida, y que por su baja productividad, el incentivo de sobre precio, no hace rentable esta actividad.

\section{$\underline{\text { Tendencia de los mercados }}$}

Si se analizan las importaciones y las exportaciones desde 1998 hasta el 2008, se encuentra:

Que las importaciones crecieron a un ritmo de 18,4 millones de cajas por año, con variaciones muy grandes entre los diferentes años, para ello se requirió hacer nuevas plantaciones por 9200 hectáreas. Por otro lado las exportaciones crecieron 16,7 millones de cajas por año, con una diferencia de 1,7 millones de cajas, ello como consecuencia de no contabilizarse las cajas exportadas por los territorios de Ultramar de la Unión Europea,y de diferencias estadísticas de las diferentes fuentes consultadas.

\section{Exportaciones e importación de Territorios de Ultramar de la Unión Europea}

Las exportaciones e importaciones de los Territorios de Ultramar de la Unión Europea, no se contabilizan, en las exportaciones e importaciones totales, ya que se consideran producción propia, pero para los países exportadores, es muy importante conocer cual ha sido la dinámica de los últimos años en ese mercado.

En los 5 años comprendidos entre el 2003, y el 2008, se observa una reducción en la producción muy drástica en Francia, bajando de 18,1 millones de cajas, a 9,4 en el 2008,ello debido a las sensibles reducciones en Martinica, desde 13,4 millones en el 2003, hasta 6,8 millones en el 2008.

En España se pasa de 23 millones en el 2004, hasta 20,4 millones en el 2008, y Grecia aumenta ligeramente su producción, Portugal se mantiene, pero no así Chipre, que las disminuye sustancialmente. En total este bloque disminuyó sus producciones desde 42 millones en el 2003, hasta 31,2 millones en el 2008 , con una reducción total del $26 \%$ en 6 años. No se prevén aumentos de producción en estos territorios para los próximos años, y ello a obligado a la Unión Europea a incrementar sus compras desde un $84 \%$ para 2003, hasta el $89,5 \%$ para el 2008 .

\section{Consumo por habitante de las importaciones}

Del cuadro en referencia, se concluye que los países desarrollados son los que tiene mayor consumo por habitante de banano importado, y es Norte América el que tiene el mayor consumo, con 11,4 kgrs, seguido por la Unión Europea 27, con 9,81 kgrs, no obstante si a esta grupo se le suman los consumos de las exportaciones de los Territorios de Ultramar, se llega a 10,92 kgrs, muy cerca del consumo de Norte América. Es importante hacer notar que el consumo en este grupo de países a crecido desde 9,32 kgrs en el 2005, hasta los 10,2 del 2008.

El otro grupo de países en importancia con respecto al consumo, es América Latina, con 8,46 kgrs, resultados de los altos consumos de Uruguay, Argentina, Chile y El Salvador.

Otro grupo importante, con consumos moderados es el de Otros, con 6,61 kgrs, donde se destaca el alto consumo de Nueva Zelanda, con 18,9 kgrs es un gran consumidor por habitante, pero que debido a su baja población, sus importaciones no son significativas, todo lo contrario de Japón, que mantiene en al redor de 8 kgrs su consumo por habitante, a través de los años, y no parece que pueda aumentarse, debido a los altos precios del mercado al consumidor.

\section{$\underline{\text { Precios }}$}

\section{Fijación del precio de los bananos.}

Hasta hace al redor de 10 años, los precios de venta de los bananos, se fijaban en Estados Unidos, en Nueva York, en base a la marca "chiquita", a partir del cual se fijaban los precios para las otras marcas, y para las otras regiones. Fue a partir de ese momento en que el sistema de mercadeo cambió, y fueron las grandes cadenas de supermercados, las que fijaron el precio para la compra de grandes volúmenes anuales, haciendo selectiva la oferta, ya que solo empresas trasnacionales con grandes ofertas y diferentes fuentes de producción, son oferentes confiables, para un mercado donde el banano es la principal fruta fresca de consumo, y que da rendimientos económicos muy altos a nivel de metro cuadrado ocupado de supermercado.

La fruta contratada, representa al redor del $70 \%$ del mercado, y se contrata en exclusiva fruta de las principales marcas, Chiquita, Dole y Del Monte; el resto de la oferta se vende "Spot" semanalmente, con la fluctuación respectiva de precios, en relación a la oferta-demanda.

Esta modificación, hizo que el mercado de oferta, se dividiera en dos sectores bien definidos, Centro América y Panamá, que venden toda su fruta 
por contrato anual, mientras que gran parte de la fruta de Ecuador y Colombia, pertenece al mercado "spot"

Este sistema de mercadeo, aunque discriminatorio, ha servido para regular la oferta, ya pequeñas variantes en oferta en un período determinado, hace que los precios varíen significativamente, al ser un mercado reducido; es por ello que los países que venden su fruta "spot", deben de ser muy cuidadosos con su oferta, ya que esas variaciones solo los afecta a ellos.

\section{Precios de los bananos en los mercados}

Analizando los precios f.o.b, de importación, al por mayor, y al detallle, para diferentes países, se encuentra, que usando a Costa Rica, como modelo de exportación, el precio es de \$7,69 f.o.b, por caja e 18,14 kgrs, mientras que para Francia los precios de importación es de $\$ 17,04$, (122\% sobre f.o.b), al por mayor $\$ 23,94$ ( $211 \%$ sobre f.o.b), y al detalle de $\$ 42,27$ ( 450\% sobre f.o.b), ello como consecuencia de a las restricciones impuestas por la Unión Europea, en 1993, a las producciones de América Latina, consecuencia de la protección que brinda el Acuerdo de Lomé, a los territorios de Ultramar y a ex colonias de algunos países europeos.

Para Japón, aunque las diferencias son un poco menores en Importación y al por mayor, son más altas al detalle, ya que su precio es de $\$ 43,27$, a ello se debe posiblemente su moderado consumo por habitante.

España, con precios más bajos, mantiene al misma relación de Francia.

Estados Unidos, es un claro ejemplo de libre mercado, donde operan las fuerzas de oferta y demanda con libertad, en ese país el precio de importación es de $\$ 15,53$ ( $102 \%$ sobre f.o.b), al por mayor, de $\$ 19,41$ ( $152 \%$ sobre f.o.b), y al detalle de $\$ 25,03$ ( $225 \%$ sobre f.o.b).Comparando precios al detalle, los precios de Francia, son 69\% mas altos que los de Estados Unidos, y los de Japón, 74\%.Es indudable que las restricciones comerciales afectan muy sensiblemente los precios al consumidor, reduciendo su demanda, y afectando las fuentes de producción en su crecimiento.

Un ejemplo de esta relación, se da en el banano orgánico vendido por Perú, a Europa

\section{Precios por marcas}

Si se analizan los precios entre las principales marcas, Chiquita, Dole y Del Monte, de otras marcas, Turbana, Banacol, Bonita, Favorita y otras, para los mercados de la Costa Este, ( 66\% del mer- cado) y Costa Oeste (33\% del mercado) de los Estados Unidos, así como de la Unión Europea 15, de alto poder económico adquisitivo y Unión Europea 10 , de moderado poder adquisitivo, y para los años 2003 y 2008 y para fruta "spot", se encuentra que los precios entre el 2003 y el 2008 se han incrementado en un $81 \%$ para principales marcas, y un $95 \%$ para otras marcas, en la Costa Este, y un $88 \%$ para principales marcas, y un $103 \%$ para otras marcas en la Costa Oeste, así mismo, el diferencial de precios entre principales marcas y otras marcas es del $46 \%$ en el 2003, y de $36 \%$ en el 2008, en la Costa Este, con datos muy semejantes para la Costa Oeste.

En la Unión Europea 15, el diferencial de precios entre el 2003 y el 2008 de las principales marcas, fue de $27 \%$, mientras que la Unión Europea 10 , fue de $69 \%$; en otras marcas ese diferencial fue $33 \%$ para UE- 15 , y de $60 \%$ en UE-10.La diferencia de precios entre principales marcas y otras marcas en ambos mercados es casi inexistente.

\section{Precios comparativos entre banano convencional y orgánico}

El diferencial de precios entre el banano convencional y el orgánico en el mercado de los Estados Unidos, es de $\$ 0,34$ por kilogramo, ya que el precio convencional es de $\$ 1,04$ por kgr, y el orgánico de $\$ 1,38$, con variaciones mensuales desde $\$ 0,13$ en el mes de Febrero, hasta $\$ 0,45$ en el mes de Octubre. En promedio se pude decir que entre el banano convencional y el orgánico, existe una diferencia de precios del $33 \%$, lo que constituye un aliciente para el productor orgánico.

\section{Precios promedio semanales}

El mercado de los Estados Unidos tiene un consumo semanal de 4 millones de cajas, de los cuales, 3 millones se consumen en la Costa Este, y 1 millón en la Costa Oeste, por lo que para este estudio se escoge la Costa Este como más representativo.

Se analiza y compara los precios "spot" semanales de los años 2009, 2010 y 26 semanas del 2011, se encuentra que los precios para las primeras 26 semanas del 2011, han sido muy superiores a los años 2009 y 2010 , con un promedio de $\$ 19$ por caja. A partir de la semana 26 y hasta la 30 , los precios del 2010 fueron muy altos, cercanos a los $\$ 20$, superando incluso al 2011, pero a partir de la semana 32, los precios se caen al nivel del 2009 , en al redor de $\$ 17$ por caja.

Proyectando los datos anteriores, es posible predecir, que los precios de las semanas 26 a la 52 
del 2011, serán superiores a los años precedentes, situándose arriba de los $\$ 17$, si los países oferentes "spot" no hacen una sobre oferta desmesurada.

El mercado de la Unión Europea 27, ha tenido un comportamiento impredecible para los años 2009,2010 y 2011, para las primeras 26 semanas del año, donde los precios para el 2009, aunque muy fluctuantes se mantenían en la redor de los \$25 por caja, semejante a los años anteriores, pero en el 2010 , los precios se caen hasta al redor de los $\$ 17$, que es muy bajo para este mercado en ese período. Los precios para ese período del 2011, arrancan muy bien en las primeras 6 semanas del año, cerca de los $\$ 24$ por caja, pero caen hasta los $\$ 15$, en la semana 26, situándose por debajo del 2010.

Los precios para las semanas 26 a 52, del año 2011, parecen comportarse muy semejantes a los de los años 2009 y 2010, y por debajo de los precios de la Costa Este de los Estados Unidos, situación que no se da desde 1993, cuando se establece la Unión Europea, y se fijan restricciones comerciales a esta producto, en ese mercado. No existe una explicación lógica al comportamiento de este mercado, ya que los problemas que afectan a la UE, son semejantes a los de USA, donde los precios más bien han mejorado. Es de esperar que una vez que la situación económica de la Unión Europea mejore, los precios repunten un poco arriba de los precios de USA, considerando el diferencial de costos de transporte, y se mantengan por un período largo.

\section{AVANCES TECNOLOGICOS DE LA BANANICULTURA}

La bananicultura por su importancia económica y social en el mundo, requiere de avances tecnológicos, acordes con su importancia, y por ello en forma muy resumida mostraré algunos de los avances recientes.

\section{Agricultura de precisión como herramienta en la toma de decisiones.}

La agricultura de precisión como herramienta en la toma de decisiones en el cultivo de banano, ha alcanzado un punto culminante; el uso normal del GPS, para posicionamiento global de problemas, con programas de pantallas y mapas con sobre posiciones (Autoswat), sensores de cosechas y de contenidos nutricionales, con supervisión de rendimientos, recopilación y representación de datos, nos permiten tener un panorama muy exacto de la situación del cultivo, y tomar las acciones correctivas a tiempo en el caso necesario, y mejorar la productividad.

\section{Renovación de plantaciones para mantener pro- ductividad.}

La renovación de plantaciones de banano para mantener la productividad, es una necesidad para todos los países productores, países como Costa Rica ya tienen programas de renovación de al redor de 7 años para todas las fincas, renovando una parte proporcional cada año. Las áreas a renovar son analizadas mediante un programa de Agricultura de Precisión, que mide niveles de productividad con relación al punto de equilibrio financiero, $\mathrm{y}$ tomar la decisión adecuada.

Las técnicas de cultivo a aplicar son las más avanzadas conocidas, como escogencia del clon adecuado a las necesidades, preparación del suelo en forma adecuado, tratando de devolverle la biodiversidad perdida mediante períodos de barbecho, cultivo en domos, siembra en doble surcos, con riego y fertirriego con micro aspersores, dotándole de un sistema de drenaje acorde a las necesidades, e inversiones en cable carril y otros sistemas de transporte. Las operaciones de cultivo son amigables con el medio ambiente, acordes con los programas nacionales de sostenibilidad, donde el cultivo de banano en Costa Rica, ocupa el primer lugar de todas las actividades agropecuarias.

\section{$\underline{\text { Nutrición de los bananos }}$}

El cultivo de bananos tiene una tasa de asimilación de fertilizantes, que apenas llega al 20\%, con la consiguiente pérdida económica y contaminación del medio ambiente; es por ello que la actividad bananera de Costa Rica, a tomado como política, reducir el consumo de agroquímicos en un $25 \%$ para los próximos 10 años.

Experiencias con fertilización orgánica, sólida (Compost,Bokashii, etc) y líquida (Bioles), reforzados con nutrimentos minerales y bilógicos, han permitido reducir el consumo de nitrogenados hasta en un $54 \%$, y de potasio hasta en un $60 \%$, sin reducir la producción, manteniendo una excelente calidad, tal y como se aprecia en el cuadro siguiente:

Al mezclar los fertilizantes orgánicos tanto sólidos como líquidos, con los minerales, se obtienen compuestos complejos del tipo de los quelatos, formados por los ácidos húmicos, y microorganismos que tienen esa propiedad, y que mejoran la tasa de asimilación de los nutrientes, y evitan en parte las pérdidas por lixiviación.

Las aplicaciones se hacen manuales al suelo, en caso de los sólidos, por fertirriego, en drench, y foliares en los líquidos. 


\section{Manejo poscosecha}

Las mejoras en poscosecha han sido determinantes en la obtención de buenas calidades, modificaciones en el sistema de protección de la fruta desde el momento de embolse hasta la cosecha, han dado resultados excelentes mejorando el aprovechamiento de la fruta con la obtención de buenas calidades. Cambios en el sistema de empaque con protectores entre los frutos, permiten manejos de frutas a grandes distancias de mercados sin deterioro. Plantas de empaque modernas, permiten una mejor utilización de la fruta, obteniendo muy buenas calidades, con bajos consumos de agua, poco deterioro ambiental y gran satisfacción de los trabajadores, tal es el caso de la planta de empaque diseñada por el autor:

El uso de ozono, para el tratamiento de aguas, permite una buena condición fitosanitaria del producto poscosecha, evitando el uso de sustancias que deterioren el medio ambiente.

\section{Producción de banano orgánico con altas tecno- logías.}

La producción de banano orgánico con altas tecnologías, permite conseguir altas productividades de muy buenas calidades, haciendo los cultivos muy rentables, tal es el caso del proyecto desarrollado por el autor en Ecuador.

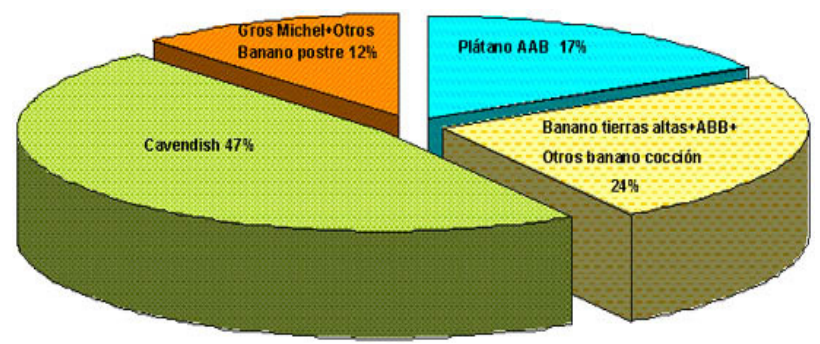

FIGURA 1: Producción mundial de musas

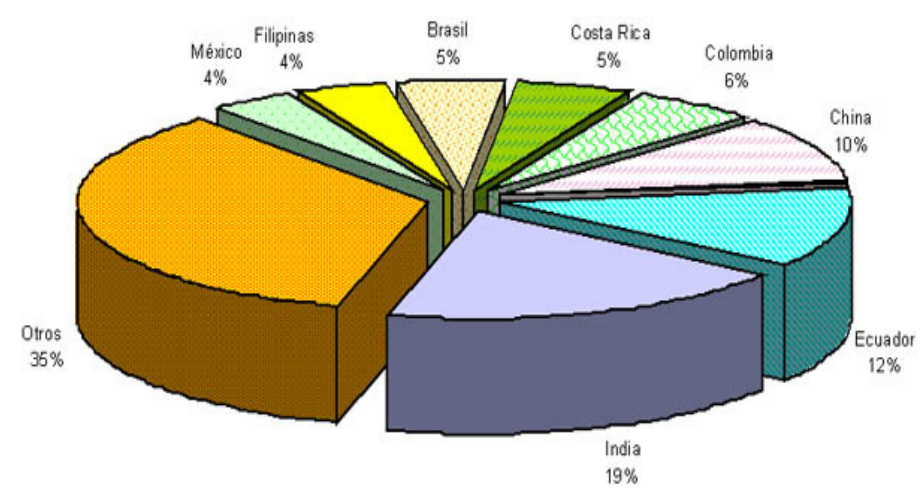

FIGURA 2: Producción de banano por países (\%) 


\section{CUADRO 1}

EXPORTACIONES MUNDIALES

Miles de cajas de 18,14 kgrs

\begin{tabular}{|c|c|c|c|c|c|c|c|c|}
\hline AÑo & 2003 & 2004 & 2005 & 2006 & 2007 & 2008 & 2009 & 2010 \\
\hline $\begin{array}{l}\text { America Latina y } \\
\text { Caribe }\end{array}$ & 574074 & 572011 & 579590 & 597597 & 639777 & 643704 & & \\
\hline America Latina & 568810 & 568711 & 579617 & 591822 & 635514 & 639556 & & \\
\hline Belice & 4120 & 4428 & 4197 & 4015 & 3361 & 9631 & & \\
\hline Brasil & 12144 & 10346 & 11660 & 10687 & 10214 & 7200 & & \\
\hline Colombia & 76923 & 76725 & 82412 & 93357 & 96206 & 98907 & & \\
\hline Costa Rica & 104572 & 98588 & 87599 & 107916 & 113372 & 103233 & 87249 & 99000 \\
\hline Republica Dominicana & 6875 & 5544 & 4774 & 11308 & 11660 & 10599 & & \\
\hline Ecuador & 232604 & 240637 & 238905 & 242132 & 255822 & 259980 & 271827 & 265588 \\
\hline Guatemala & 52773,2 & 56212,3 & 62603,1 & 54043 & 73172 & 74508,5 & & \\
\hline Honduras & 24387 & 29024 & 27935 & 28391 & 31356 & 33385 & & \\
\hline Mexico & 1622,5 & 2508 & 0 & 3663 & 2288 & 4840 & 7959 & \\
\hline Nicaragua & 2249,5 & 2261 & 2288 & 2074 & 2288 & 4840 & & \\
\hline Panamá & 22561 & 21890 & 19740 & 23711 & 24123 & 20163 & & \\
\hline Perú & 995,5 & 1496 & 2349 & 3141 & 3603 & 4301 & & \\
\hline Surinam & 0 & 1067 & & 2607 & 3091 & 3597 & 3647 & \\
\hline Venezuela & 1116,5 & 1980 & & 644 & 583 & 77 & & \\
\hline Otros & 1562 & 2349 & & 4191 & 4362 & 4725 & & \\
\hline Caribe & 6545 & 6077 & 4075 & 5770 & 3663 & 4037 & & \\
\hline Jamaica & 2305 & 1579 & 638 & 1755 & 957 & 22 & & \\
\hline Dominica & 737 & 798 & 776 & 776 & 528 & 671 & & \\
\hline Grenadas & 22 & 22 & 0 & 17 & 11 & 27,5 & & \\
\hline Santa Lucia & 1914 & 2360 & 1705 & 1920 & 1408 & 2266 & & \\
\hline $\begin{array}{l}\text { San Vicente y } \\
\text { Granadinas }\end{array}$ & 1568 & 1320 & 957 & 1309 & 1364 & 1177 & & \\
\hline Lejano Este & 106793 & 104896 & & 133524 & 127903 & 128838 & & \\
\hline China & 2915 & 2288 & & 2150,5 & 1958 & 1705 & & \\
\hline Malasia & 1353 & 1804 & & 1474 & 1490,5 & 1656 & & \\
\hline Paquistan & 396 & 330 & 468 & 655 & 363 & 2008 & & \\
\hline Filipinas & 92026,5 & 94873 & 107475 & 115098 & 110062 & 106665,7 & 112039 & 110965,8 \\
\hline Tailandia & 203,5 & 468 & & 1117 & 1177 & 1161 & 1205 & \\
\hline Vietnam & 693 & 396 & & 116 & 88 & 88 & & \\
\hline Otros & 616 & 759 & & 875 & 847 & 1628 & & \\
\hline Africa & 30839 & 29249 & 27747 & 33314 & 29200 & 30344 & & \\
\hline Camerun & 17254 & 16220 & 14163 & 14113 & 12227 & 15417 & & \\
\hline Costa de Marfil & 13349 & 12601 & 11600 & 15752 & 15994 & 14537 & & \\
\hline Etiopia & 72 & 72 & & 28 & 143 & 110 & & \\
\hline Guinea & 0 & 0 & & 0 & 0 & 0 & & \\
\hline Somalia & 0 & 0 & & 0 & 0 & 0 & & \\
\hline Otros & 165 & 358 & 253 & 3416 & 842 & 281 & & \\
\hline Oceanía & 6 & 6 & 6 & 6 & 6 & 6 & & \\
\hline MUNDO & 711706 & 706156 & 731170 & 764434 & 796890 & 802890 & & \\
\hline
\end{tabular}




\section{CUADRO 2}

VARIACION DE LA OFERIA MUNDIAL Y PROYECCION Miles de toneladas

\begin{tabular}{|c|c|c|c|c|c|c|c|c|}
\hline \multicolumn{9}{|c|}{ Miles de toneladas } \\
\hline & & & & 1983-2008 & & & & \\
\hline PAISES & 1983-1985 & 1993-1995 & 1996 & $\begin{array}{l}\text { Crec. Anual } \\
83-85 / 93-95\end{array}$ & 2005 & $\begin{array}{l}\text { Crec. Anual } \\
93-95 / 2005\end{array}$ & 2008 & \begin{tabular}{|l|} 
Crec.Anual \\
$2005 / 2008$ \\
\end{tabular} \\
\hline TOTAL & 5,858 & 10,754 & 11,478 & $6.26 \%$ & 13,294 & $2.24 \%$ & 14,598 & $3,27 \%$ \\
\hline Ecuador & 993 & 3,209 & 3,842 & $12.44 \%$ & 4653,9 & $3.76 \%$ & 4726,9 & 0,50 \\
\hline costa Rica & 896 & 1,914 & 1,933 & $7.88 \%$ & 1614,5 & $1.70 \%$ & 1869,2 & 5,26 \\
\hline Colombia & 834 & 1,470 & 1,407 & $5.83 \%$ & 1621,5 & $0.94 \%$ & 1798,3 & 3,63 \\
\hline Guatemala & 312 & 635 & 611 & $101,70 \%$ & \# & $77,79 \%$ & 1354,7 & 9,80 \\
\hline Panama & 663 & 723 & 643 & $0.8 / \%$ & 348,3 & $0.89 \%$ & 366,6 & 1,75 \\
\hline Resto Mundo & 2,472 & 3,438 & 3,653 & $3.50 \%$ & 4009,5 & $1.59 \%$ & 4482,3 & 3,93 \\
\hline
\end{tabular}

\section{CUADRO 3}

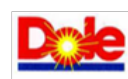

America Latina - Estimación de la

Producción Exportada en el 2009 Banano Orgánico

\begin{tabular}{lcc}
\hline \multicolumn{1}{c}{ País } & $\begin{array}{c}\text { PRODUCcIón } \\
\text { (Millones) }\end{array}$ & $\begin{array}{c}\text { AREA TOTAL } \\
\text { (Has) }\end{array}$ \\
\hline Ecuador & 9.9 & 10.500 \\
Dom Rep & 5.5 & 5.100 \\
Perú & 4.1 & 5.250 \\
Colombia & 3.2 & 2.250 \\
\multicolumn{1}{c}{ TOTAL } & 24.2 & 23.750
\end{tabular}

Promedio $=1019$ Cajas $/ \mathrm{Ha} /$ Año

\section{Dele DOLE's Banano Organico} Volumen 1997-2008

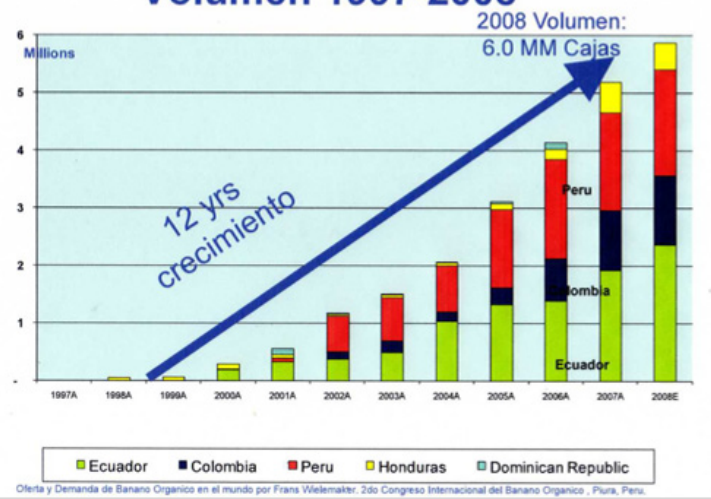

FIGURA 3: Crecimiento de exportaciones de banano orgánico 
CUADRO 4

\section{CORBANA}
IMPORTACIÓN MUNDIAL DE BANANO SEGÚN REGIÓN
2007 y 2008
Toneladas

\begin{tabular}{lrrrrrr|}
\hline \multicolumn{1}{c}{ Región } & \multicolumn{2}{c}{2007} & \multicolumn{2}{c}{2008} & \% variación \\
& Volumen * & Participación & Volumen * & Participación & 2007-2008 \\
\hline Unión Europea & $4,678,013$ & $33.2 \%$ & $4,848,975$ & $33.2 \%$ & $3.7 \%$ \\
Estados Unidos y Canadá & $4,733,069$ & $33.6 \%$ & $4,728,194$ & $32.4 \%$ & $-0.1 \%$ \\
Asia & $2,028,446$ & $14.4 \%$ & $2,325,063$ & $15.9 \%$ & $14.6 \%$ \\
Resto de Europa & $1,561,253$ & $11.1 \%$ & $1,588,682$ & $10.9 \%$ & $1.8 \%$ \\
América Latina & 819,898 & $5.8 \%$ & 824,490 & $5.6 \%$ & $0.6 \%$ \\
Átrica & 201,931 & $1.4 \%$ & 206,905 & $1.4 \%$ & $2.5 \%$ \\
Resto del Mundo & 81,093 & $0.6 \%$ & 80,404 & $0.6 \%$ & $-0.8 \%$ \\
TOTAL & $14,103,703$ & $100.0 \%$ & $14,602,713$ & $100.0 \%$ & $3.5 \%$
\end{tabular}

* Los volúmenes de importación son estimados.

Fuente: CORBANA, Sección de Estadisticas.

\section{CUADRO 5}

IMPORTACIONES MUNDIALES

\begin{tabular}{|c|c|c|c|c|c|c|c|}
\hline \multicolumn{8}{|c|}{ Cajas de 18,14 kgrs } \\
\hline ANO & 2003 & 2004 & 2005 & 2006 & 2007 & 2008 & 2009 \\
\hline Países en des arrollo & 129327 & 117937 & 141130 & 145689 & 139447 & 144435 & \\
\hline America Latina & 33545 & 33721 & 33027 & 30932 & 32906 & 34292 & \\
\hline Argentina & 15752 & 16687 & 16621 & 16263 & 17539 & 19074 & 10 \\
\hline Chile & 8679 & 8784 & 19741 & 9289 & 9801 & 9625 & 5 \\
\hline El Salvador & 5907 & 5753 & 2920 & 3 & 3 & 3 & \\
\hline Uruguay & 2 & 2 & 3 & 2 & 2 & 2 & \\
\hline Otros & 1 & $\mathbf{0}$ & $\mathbf{0}$ & 0 & 0 & 0 & \\
\hline Cercano Este & 43 & 47 & 58 & 62 & 53 & 52 & \\
\hline Irán & 15 & 15 & 25 & 16 & 11 & & \\
\hline Arabia Saudita & 11 & 12 & 13 & 13 & 14 & & \\
\hline Siria & 4 & 5 & 6 & 18 & 11 & & \\
\hline Turquia & 5 & 6 & 8 & 9 & 12 & 13 & \\
\hline Emiratos Arabes & 4 & 4 & 2 & $\mathbf{0}$ & $\mathbf{0}$ & $\mathbf{0}$ & \\
\hline Otros & 1 & 1 & 2 & 2 & 3 & 4 & \\
\hline Lejano Este & 41982 & 37433 & 387 & 41954 & 40299 & 43093 & \\
\hline China & 12705 & 20950 & 19564 & 21319 & 18255 & 19927 & 11098 \\
\hline China-Hong Kong & 3185 & 2997 & 3146 & 3108 & 2937 & 3993 & \\
\hline China-Macao & 110 & 99 & 66 & 127 & 110 & 110 & \\
\hline Corea & 12100 & 11457 & 13932 & 15329 & 16957 & 16966 & \\
\hline Singapur & 1936 & 1925 & 1964 & 2008 & 2041 & 2112 & \\
\hline Africa & 14350 & 15351 & 11248 & 10709 & 13437 & 13140 & \\
\hline Argelia & 12281 & 11253 & 8641 & 8096 & 8943 & 8943 & \\
\hline Marruecos & 61 & 121 & 270 & 297 & 946 & 979 & \\
\hline Sengal & 677 & 776 & 825 & 864 & 930 & 930 & \\
\hline Tunisia & 759 & 2987 & 1144 & 1117 & 2255 & 1843 & \\
\hline Burquina Faso & 66 & 28 & 44 & 1513 & 3630 & $\mathbf{0}$ & \\
\hline Países Desarrollados & 559103 & 567325 & 572512 & 601948 & 643522 & 655419 & \\
\hline CE 15 & 184602 & 186896 & & & & & \\
\hline CE 25 & & 200415 & 205277 & 229713 & & & \\
\hline CE 27 & & & 205007 & 240680 & 257532 & 266970 & \\
\hline Otros Europa & 49594 & 53108 & 28606 & 29381 & 30399 & 29623 & \\
\hline Albania & 1249 & 946 & 924 & 924 & 1111 & 957 & \\
\hline Bulgaria & 2717 & 2745 & 3014 & 2690 & 2145 & 2239 & \\
\hline
\end{tabular}




\begin{tabular}{|c|c|c|c|c|c|c|c|}
\hline República Checa & 5902 & 5907 & & & & & \\
\hline Hungria & 4362 & 3982 & & & & & \\
\hline Is landia & 226 & 253 & 259 & 297 & 303 & 308 & \\
\hline Malta & 363 & 270 & & & & & \\
\hline Noruega & 3487 & 3641 & 4026 & 4103 & 4318 & 4593 & \\
\hline Polonia & 13866 & 11402 & & & & & \\
\hline Rumanía & 2360 & 5599 & 7876 & 8487 & 8602 & 6991 & \\
\hline Slovaquia & 2761 & 2558 & & & & & \\
\hline Suiza & 3971 & 4043 & 4081 & 4076 & 4301 & 4516 & \\
\hline Yugos lavia & 8333 & 8932 & 8426 & 8811 & 9620 & 10021 & \\
\hline Bosnia & & & 2470 & 2079 & 2107 & 2244 & \\
\hline Croacia & 2783 & 2794 & 2970 & 2833 & 3014 & 3135 & \\
\hline Macedonia & 842 & 1144 & 968 & 831 & 886 & 847 & \\
\hline Slovenia & 1601 & 2299 & & & & & \\
\hline Servia & & & 2019 & 3069 & 3614 & 3740 & \\
\hline Ex USSR & 53807 & 54527 & 65181 & 68459 & 75873 & 76742 & \\
\hline Armenia & 72 & 215 & 418 & 303 & 820 & 457 & \\
\hline Azerbaijan & 88 & 259 & & & & & \\
\hline Belarus & 1150 & 688 & 1579 & 1617 & 1826 & 2294 & \\
\hline Estonia & 671 & 748 & & & & & \\
\hline Georgia & & & 479 & 517 & 561 & 457 & \\
\hline Kas akhstan & & & 1183 & 1386 & 1898 & 2090 & \\
\hline Latvia & 1023 & 363 & & & & & \\
\hline Federación Rusa & 43285 & 46519 & 46904 & 48593 & 52784 & 54368 & \\
\hline Norte América & 213059 & 212569,5 & 210303,5 & 211838 & 220698 & 216205 & \\
\hline Canadá & 23254 & 24233 & 24695 & 25118 & 25817 & 26268 & 19943 \\
\hline Estados Unidos & 189810,5 & 188331 & 185614 & 186725 & 194281 & 189937 & 121154 \\
\hline Otros & 58036 & 60230,5 & 63217 & 62557 & 108515 & 65851 & \\
\hline Japón & 54263 & 56430 & 58679,5 & 57398 & 53383 & 60115 & \\
\hline Nueva zelanda & 4191 & 3641 & 4268 & 4449 & 4427 & 4400 & \\
\hline Sur Africa & 1 & 2 & 3 & 8 & 12 & 13 & \\
\hline MUNDO & 688430 & 685267 & 713636 & 747637 & 782952 & 799854 & \\
\hline
\end{tabular}

\section{CUADRO 6}

VARIACION DE LA DEMANDA MUNDIAL Y PROYECCIONES

Miles de toneladas

\begin{tabular}{|c|c|c|c|c|c|c|c|c|}
\hline PAISES & 1983-1985 & 1993-1995 & 1996 & \begin{tabular}{|l|} 
Crec. Anual \\
$83-85 / 93-95$
\end{tabular} & 2005 & $\frac{\text { Crec. Anual }}{9 3 - 9 5 \longdiv { 2 0 0 5 }}$ & 2008 & \begin{tabular}{|l|} 
Crec.Anual| \\
$2005 / 2008$
\end{tabular} \\
\hline TOTAL & 5986 & 10337 & 10870 & $5,62 \%$ & 12975 & $1,94 \%$ & 14542,8 & $4,03 \%$ \\
\hline $\begin{array}{l}\text { Union Europea } \\
(15)(25)(27)\end{array}$ & 1,875 & 3,108 & $\overline{3,158}$ & $5.19 \%$ & 3733 & $0.85 \%$ & 4854,6 & $10,02 \%$ \\
\hline Otros Europa & 80 & 724 & 753 & $24.70 \%$ & 858 & $1.55 \%$ & 538,6 & $12,40 \%$ \\
\hline USA & 2,468 & 3,237 & 3,368 & $2.75 \%$ & 3374 & $2.06 \%$ & 3453,4 & $2,36 \%$ \\
\hline Japón & 646 & 905 & 819 & $3.43 \%$ & 1149 & $0.99 \%$ & 1193,0 & $1,27 \%$ \\
\hline Resto Mundo & 917 & 2,363 & 2,772 & $4.50 \%$ & 3862 & $-5.85 \%$ & 4503,2 & $5,54 \%$ \\
\hline
\end{tabular}

CUADRO 7

TENDENCIA DE LOS MERCADOS BANANEROS

\begin{tabular}{|c|c|c|c|c|c|c|c|}
\hline \multirow[t]{2}{*}{ AÑO } & \multirow[t]{2}{*}{ IMPORTACIONES } & \multicolumn{2}{|c|}{ INCREMENTO POR AÑO } & \multicolumn{3}{|c|}{ EXPORTACIONES INCREMENTO POR AÑO } & \multirow{2}{*}{$\begin{array}{c}\text { DIFERENCIA POR AÑO * } \\
\text { IMPOR/EXPORT }\end{array}$} \\
\hline & & \begin{tabular}{|l|} 
CAJAS \\
\end{tabular} & $\%$ & & \begin{tabular}{|l|} 
CAJAS \\
\end{tabular} & $\%$ & \\
\hline 1998 & 615.824 .000 & & & 635.316 .000 & & & -19.492 .000 \\
\hline 1999 & 657.574 .500 & 47750500 & 7,74 & 650.419 .000 & 15.103 .000 & 2,38 & 7.155 .500 \\
\hline 2000 & 671.682 .000 & 14107500 & 2,14 & 655.715 .500 & 5.296 .500 & 0,81 & 15.966 .500 \\
\hline 2001 & 638.379 .500 & 33302250 & 4,95 & 639.199 .000 & -16.516 .500 & $-2,52$ & -819.500 \\
\hline 2002 & 650.171 .500 & 11792000 & 1,82 & 673.827 .000 & 34.628 .000 & 5,42 & -23.655 .500 \\
\hline 2003 & 687.357 .000 & 37185500 & 5,72 & 713.383 .000 & 39.556 .000 & 5,87 & -26.026 .000 \\
\hline 2004 & 700.216 .000 & 12859000 & 1,87 & 710.264 .500 & -3.118 .500 & $-0,44$ & -10.048 .500 \\
\hline 2005 & 713.636 .000 & 13420000 & 1,92 & 731.170 .000 & 20.905 .500 & 2,94 & -17.534 .000 \\
\hline 2006 & 747.582 .000 & 33946000 & 4,76 & 764.434 .000 & 33.264 .000 & 4,55 & -16.852 .000 \\
\hline 2007 & 782.952 .500 & 35370500 & 4,73 & 796.889 .500 & 32.455 .500 & 4,25 & -13.937 .000 \\
\hline 2008 & 799.854 .000 & 16901500 & 2,16 & 802.890 .000 & 6.000 .500 & 0,75 & -3.036 .000 \\
\hline TOTAL & 7.665.229.000 & 18.403 .000 & 2,30 & 7.773.507.500 & 16.757 .400 & 2,63 & 10.827 .850 \\
\hline
\end{tabular}

* DIFERENCIAS POR IMPORTACIONES DE TERRITORIOS DE ULTRAMAR DE LA UNIÓN EUROPEA 


\section{CUADRO 8}

EXPORTACIONES DE TERRITORIOS DE ULTRAMAR

E IMPORTACIONES NETAS DE LA UNIÓN EUROPEA

MILES DE CAJAS DE 18,14 KGRS

\begin{tabular}{|l|r|r|r|r|r|r|}
\hline & 2003 & 2004 & 2005 & 2006 & 2007 & 2008 \\
\hline & & & & & & \\
\hline FRANCIA & 18106,0 & 16791,5 & 15427,5 & 14773,0 & 9201,5 & 9410,5 \\
\hline Guadapupe & 4702,5 & 3250,5 & 2981,0 & 2629,0 & 2090,0 & 2557,5 \\
\hline Martinica & 13403,5 & 13541,0 & 12441,0 & 12144,0 & 7111,5 & 6847,5 \\
\hline ESPAÑA & 22049,5 & 23012,0 & 18975,0 & 19151,0 & 19877,0 & 20405,0 \\
\hline GRECIA & 148,5 & 159,5 & 159,5 & 159,5 & 159,5 & 220,0 \\
\hline CHIPRE & 616,0 & 577,5 & 319,0 & 357,5 & 330,0 & 220,0 \\
\hline PORTUGAL & 1177,0 & 1166,0 & $\mathbf{7 8 1 , 0}$ & 841,5 & 946,0 & 935,0 \\
\hline PRODUCCIÓN & $\mathbf{4 2 0 9 7 , 0}$ & $\mathbf{4 1 7 0 1 , 0}$ & $\mathbf{3 5 6 6 2 , 0}$ & $\mathbf{3 5 2 8 8 , 0}$ & $\mathbf{3 0 5 0 8 , 5 0}$ & $\mathbf{3 1 1 8 5 , 0}$ \\
\hline
\end{tabular}

IMPORTACIONES NETAS

\begin{tabular}{|l|r|r|r|r|r|r|}
\hline EC (27) & 221375,0 & 220379,5 & 215611,0 & 240190,5 & 256778,5 & 266194,5 \\
\hline CONSUMO NETO & 263450,0 & 262075,0 & 251295,0 & 275495,0 & 287265,0 & 297385,0 \\
\hline \% IMPORTADO & 84,0 & 84,1 & 85,8 & 87,2 & 89,4 & 89,5 \\
\hline CONSUMO/HABITANTE & $\mathbf{9 , 8 5}$ & $\mathbf{9 , 7 6}$ & $\mathbf{9 , 3 2}$ & $\mathbf{1 0 , 1 8}$ & $\mathbf{1 0 , 5 9}$ & $\mathbf{1 0 , 9 2}$ \\
\hline
\end{tabular}

\section{CUADRO 9}

\section{IMPORTACIONES POR HABITANTE}

\begin{tabular}{|c|c|c|c|c|c|c|c|c|c|}
\hline & & (KGRS/ & CAP) & & & & & & \\
\hline AÑO & 2000 & 2001 & 2002 & 2003 & 2004 & 2005 & 2006 & 2007 & 2008 \\
\hline Países en des arrollo & 1,25 & 1,07 & 1,07 & 1,27 & 1,28 & 1,37 & 1,4 & 1,33 & 1,37 \\
\hline America Latina & 9,32 & 8,75 & 7,17 & 7,95 & 7,93 & 8,38 & 7,77 & 8,19 & 8,46 \\
\hline Argentina & 9,21 & 8,86 & 6,1 & 7,54 & 7,9 & 7,8 & 7,56 & 8,07 & 10,4 \\
\hline Chile & 12.65 & 9.56 & 9.55 & 9.98 & 9.99 & 12 & 10,26 & 10,7 & 10,4 \\
\hline 曰Salvador & 9.51 & 9.70 & 8.58 & 16.49 & 15.81 & 8,77 & 8,07 & 8,81 & 8,75 \\
\hline Uruguay & 9.87 & 14.54 & 12.91 & 12.04 & 12.70 & 14,2 & 13,39 & 12,6 & 12,9 \\
\hline Otros & 1.70 & 2.23 & 2.37 & 2.39 & 0.23 & 0,35 & 0,55 & 0,73 & 0,66 \\
\hline Cercano Este & 2.44 & 1.69 & 1.76 & 2.47 & 1.82 & 3,37 & 3,56 & 2,95 & 2,96 \\
\hline Chipre & 0.94 & 0.99 & 1.23 & 1.13 & 2.78 & & & & \\
\hline Irán & 3.01 & 1.12 & 2.21 & 4.17 & 3.48 & 6,49 & 4,19 & 0,29 & 0,28 \\
\hline Kuw ait & 10.39 & 10.05 & 2.28 & 0.15 & 0.21 & & & & \\
\hline Libano & 0.60 & 0.05 & 0.05 & 0.10 & 0.29 & & & & \\
\hline Libia & 2.19 & 4.91 & 0.09 & 0.01 & 0.04 & & & & \\
\hline Arabia Saudita & 8.44 & 7.93 & 7.50 & 8.23 & 4.47 & 9,88 & 9,72 & 10,1 & 9,84 \\
\hline Siria & 4.15 & 3.12 & 2.75 & 3.96 & 4.48 & 5,91 & 16,63 & 9,4 & 9,08 \\
\hline Turquía & 1.82 & 0.60 & 0.92 & 1.29 & 1.52 & 2,07 & 2,34 & 3,07 & 2,96 \\
\hline Emiratos Arabes & 24.29 & 27.66 & 23.26 & 23.59 & & 10,8 & & 28,2 & 28,3 \\
\hline Egipto & 0.08 & 0.08 & 0.04 & 0.02 & 0.02 & & & & \\
\hline Otros & 0.14 & 0.12 & 0.06 & 0.03 & 0.04 & 0,35 & 0,46 & 0,6 & 0,83 \\
\hline Lejano Es te & 5,11 & 5,16 & 4,86 & 5,21 & 4,95 & 4,93 & 5,45 & 5,33 & 5,84 \\
\hline China & 0.47 & 0.32 & 0.27 & 0.32 & 0.29 & 0,27 & 0,29 & 0,25 & 0,27 \\
\hline China Hong Kong & 6.92 & 7.51 & 7.42 & 8.22 & 7.66 & 8,32 & 8,47 & 7,68 & 10,4 \\
\hline China Macao & 3.71 & 4.09 & 3.65 & 4.25 & 3.92 & 2,53 & 4,59 & 4,01 & 3,8 \\
\hline Corea & 3.93 & 4.13 & 3.95 & 4.61 & 3.4. & 5,29 & 5,85 & 6,43 & 6,4 \\
\hline Singapur & 10.52 & 9.69 & 8.98 & 8.27 & 8.11 & 8,26 & 8,33 & 8,27 & 8,31 \\
\hline Africa & 2,37 & 1,8 & 2,43 & 2,45 & 2,99 & 2,31 & 2,21 & 2,77 & 2,73 \\
\hline Argelia & & 2.78 & 7.40 & 7.02 & & 4,78 & 4,41 & 4,8 & 4,73 \\
\hline Marruecos & & 0.10 & 0.05 & 0.04 & 0.07 & 0,16 & 0,17 & 0,55 & 0,56 \\
\hline Senegal & 0.76 & 1.09 & 1.22 & 1.22 & 1.37 & 1,27 & 1,36 & 1,4 & 1,39 \\
\hline Tunisia & 1.63 & 1.15 & 1.67 & 1.40 & 5.46 & 2,06 & 1,98 & 4,07 & 3,3 \\
\hline Burquina Faso & 0.63 & 0.28 & & 0.10 & 0.05 & 0,06 & 0,04 & 0,08 & 0,08 \\
\hline Otros & 6.56 & 5.56 & & 5.10 & & & & & \\
\hline
\end{tabular}




\begin{tabular}{|c|c|c|c|c|c|c|c|c|c|}
\hline Países desarrollados & 7.72 & 7.46 & 7.59 & 7.80 & 7.86 & 7,91 & 8,27 & 8,61 & 8,74 \\
\hline CE 15 & 8.65 & 8.37 & 8.57 & 8.83 & 8.92 & & & & \\
\hline CE 25 & 8,53 & 8,23 & 8,29 & 8,6 & 8,39 & 8,09 & 9,03 & & \\
\hline CE 27 & & & & & & & & 9,49 & 9,81 \\
\hline Otros Europa & 6.38 & 6.40 & 6.78 & 6.78 & 6.88 & 7,93 & 8,15 & 8,44 & 8,23 \\
\hline Albania & 5.73 & 2.71 & 5.95 & 7.17 & 5.37 & 5,33 & 5,31 & 6,44 & 5,53 \\
\hline Bulgaria & 3.14 & 3.43 & 4.13 & 6.26 & 6.38 & 7,07 & 6,35 & 5,11 & 5,36 \\
\hline República Checa & 9.95 & 9.56 & 9.82 & 10.48 & 10.50 & & & & \\
\hline Hungría & 8.11 & 7.43 & 7.10 & 8.03 & 7.37 & & & & \\
\hline Islandia & 12.41 & 12.82 & 14.01 & 14.14 & 15.78 & 16 & 17,78 & 17,9 & 17,6 \\
\hline Malta & 19.17 & 17.84 & 17.67 & 14.14 & 15.78 & & & & \\
\hline Noruega & 13.39 & 13.56 & 13.25 & 13.98 & 14.55 & 15,8 & 15,99 & 16,6 & 17,5 \\
\hline Polonia & 7.13 & 6.77 & 6.06 & 6.53 & 5.38 & & & & \\
\hline Rumanía & 2.08 & 2.36 & 2.85 & 1.92 & 4.57 & 6,62 & 7,17 & 7,29 & 5,95 \\
\hline Slovaquia & 8.14 & 8.40 & 8.46 & 9.28 & 8.60 & & & & \\
\hline Suisa & 10.08 & 10.24 & 10.36 & 10.07 & 10.26 & 10 & 9,9 & 10,4 & 10,9 \\
\hline Conf Yugoslavia & 4.99 & 6.08 & 8.36 & 6.54 & 7.01 & 7,39 & 7,74 & 8,45 & 8,8 \\
\hline Croacia & 9.42 & 9.72 & 10.15 & 11.43 & 11.51 & & & & \\
\hline Macedonia & 2.52 & 1.00 & & 7.45 & 10.05 & & & & \\
\hline Slovenia & 23.81 & 13.31 & 14.03 & 14.67 & 21.08 & & & & \\
\hline EXUSSR & 2.31 & 2.56 & 2.76 & 3.40 & 3.46 & 4,26 & 4,49 & 4,98 & 5,04 \\
\hline Armenia & 0.51 & 0.33 & 0.60 & 0.44 & 1.28 & 2,52 & 1,8 & 4,84 & 2,68 \\
\hline Azerbaijan & 0.39 & 0.13 & 0.04 & 0.19 & 0.56 & & & & \\
\hline Belarus & 3.10 & 1.73 & 1.62 & 2.11 & 1.27 & 2,93 & 0,01 & 3,42 & 4,31 \\
\hline Estonia & 8.19 & 7.51 & 6.83 & 9.21 & 10.37 & & & & \\
\hline Latvia & 8.21 & 6.33 & 6.01 & 8.08 & 2.01 & & & & \\
\hline Federación Rusa & 3.43 & 4.19 & 4.45 & 5.49 & 5.94 & 5,96 & 6,2 & 6,76 & 6,99 \\
\hline Norte América & 12.76 & 12.03 & 12.12 & 11.90 & 11.95 & 11,5 & 11,38 & 11,8 & 11,4 \\
\hline Canadá & 12.95 & 13.05 & 13.34 & 13.42 & 13.88 & 13,9 & 14 & 14,3 & 14,4 \\
\hline Estados Unidos & 12.74 & 11.92 & 11.99 & 11.74 & & 11,3 & 11,11 & 11,5 & 11,1 \\
\hline Otros & 6.57 & 6.07 & 5.71 & 5.98 & 6.19 & 6,39 & 6,31 & 5,94 & 6,61 \\
\hline Japón & 8.49 & 7.78 & 7.34 & 7.73 & 8.04 & 8,34 & 8,19 & 7,62 & 8,39 \\
\hline Nueva Zelanda & 17.87 & 18.92 & 17.51 & 17.33 & 16.95 & 18,9 & 19,47 & 19,2 & 18,9 \\
\hline Sur Africa & 0.06 & 0.06 & 0.05 & 0.04 & 0.06 & 0,1 & 0,26 & 0,45 & 0,49 \\
\hline MUNDO & 3,96 & 3,73 & 3,78 & 3,96 & 4,02 & 4,07 & 4,24 & 4,34 & 4,43 \\
\hline
\end{tabular}

\section{CUADRO 10}

PRECIOS DE IMPORTACIÓN, AL POR MAYOR Y AL DETALLE US $\$ /$ Caja de 18,14 kg (2009)

\begin{tabular}{|l|c|c|c|c|}
\hline PAÍS & FOB & IMPORTACIÓN & AL POR MAYOR & AL DETALLE \\
\hline COSTA RICA & 7,69 & & & \\
\hline FRANCIA & & 17,04 & 23,94 & 42,27 \\
\hline JAPÓN & & 15,55 & 29,39 & 43,54 \\
\hline USA & & 15,53 & 19,41 & 25,03 \\
\hline ESPAÑA & & 15,36 & 19,95 & 36,46 \\
\hline PROMEDIO & 7,69 & 15,87 & 23,17 & 36,83 \\
\hline INCREMENTO \% & & 106 & 46 & 59 \\
\hline
\end{tabular}




\section{Quién se lle, la mayor tajada?}

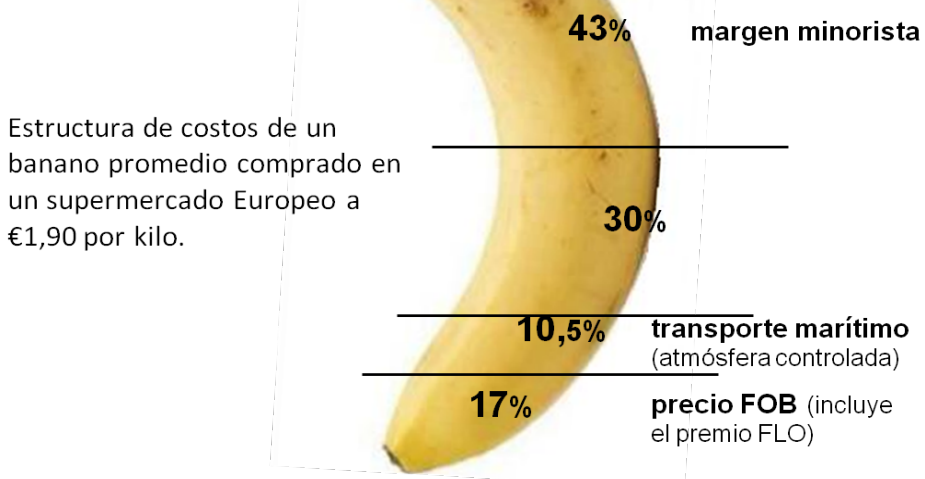

FIGURA 4: Descomposición del precio al detalle de banano orgánico

\section{CUADRO 11}

DIFERENCIA DE PRECIO POR MARCAS

US \$/CAJA DE 18,14 KGRS

\begin{tabular}{|c|c|c|c|c|c|c|c|c|c|c|c|c|}
\hline Marcas & \multicolumn{3}{|c|}{ Este USA } & \multicolumn{3}{|c|}{ Oeste USA } & \multicolumn{3}{|c|}{ UE 15} & \multicolumn{3}{|c|}{ UE 10} \\
\hline & 2003 & 2008 & inc \% & 2003 & 2008 & inc \% & 2003 & 2008 & inc \% & 2003 & 2008 & inc \% \\
\hline Principal & 6,8 & 12,32 & 81 & 6,75 & 12,68 & 88 & 15,4 & 19,55 & 27 & 8,72 & 14,72 & 69 \\
\hline Otras & 4,65 & 9,06 & 95 & 4,62 & 9,36 & 103 & 14,7 & 19,55 & 33 & 9,09 & 14,51 & 60 \\
\hline \multirow[t]{3}{*}{ inc \% } & 46 & 36 & & 46 & 35 & & 5 & 0 & & 4 & & \\
\hline & \multicolumn{6}{|c|}{ Principales marcas:Dole, Chiquita,Del Monte } & & & & & & \\
\hline & \multicolumn{3}{|c|}{ Otras marcas } & \multicolumn{5}{|c|}{ :Turbana, Banacol,Bonita, Faborita, etc } & & & & \\
\hline
\end{tabular}

\section{CUADRO 12}

PRECIOS DE LOS BANANOS ORGANICOS Y CONVENCIONALES

AL POR MAYOR US $\$ / \mathrm{kg}$ (2008)

\begin{tabular}{|l|c|c|c|r|}
\hline \multirow{2}{*}{ MES } & \multicolumn{2}{|c|}{ USA } & \multicolumn{1}{c|}{ DIFERENCIA } \\
\cline { 2 - 5 } & Convencional & Orgánico & $\$$ & $\%$ \\
\hline Enero & 0,75 & 1,12 & 0,37 & 49 \\
\hline Mebrero & 0,99 & 1,12 & 0,13 & 13 \\
\hline Abrio & 1,36 & 1,54 & 0,18 & 13 \\
\hline Mayo & 1,33 & 1,60 & 0,27 & 20 \\
\hline Junio & 1,28 & 1,47 & 0,19 & 15 \\
\hline Julio & 1,06 & 1,52 & 0,46 & 43 \\
\hline Agosto & 0,96 & 1,37 & 0,41 & 43 \\
\hline Setiembre & 0,93 & 1,36 & 0,43 & 46 \\
\hline Octubre & 0,94 & 1,38 & 0,44 & 47 \\
\hline Noviembre & 0,96 & 1,38 & 0,42 & 44 \\
\hline Diciembre & 0,93 & 1,38 & 0,45 & 48 \\
\hline Año & 0,93 & 1,34 & 0,41 & 44 \\
\hline Caja de 18,14 kg & 1,04 & 1,38 & 0,34 & 33 \\
\hline
\end{tabular}




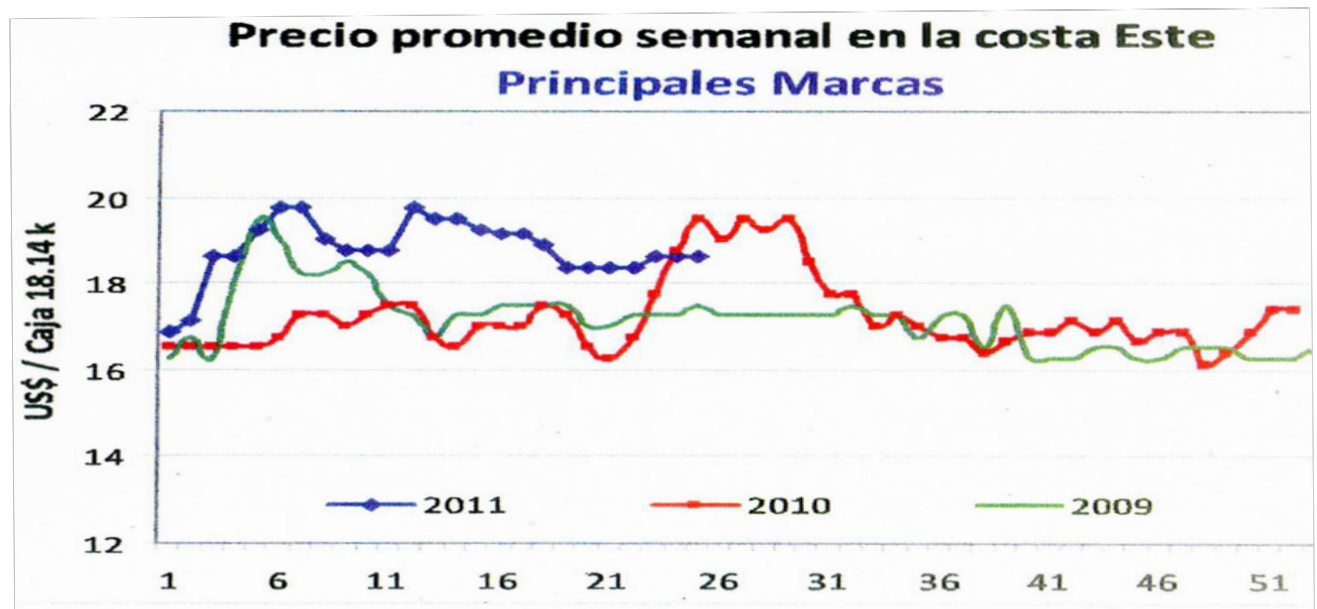

Fuente: Elaborado por la Sección de Estadísticas de CORBANA S.A. con datos de SOPISCC

FIGURA 5: Precio promedio semanal "spot" en Costa Este U.S.A.

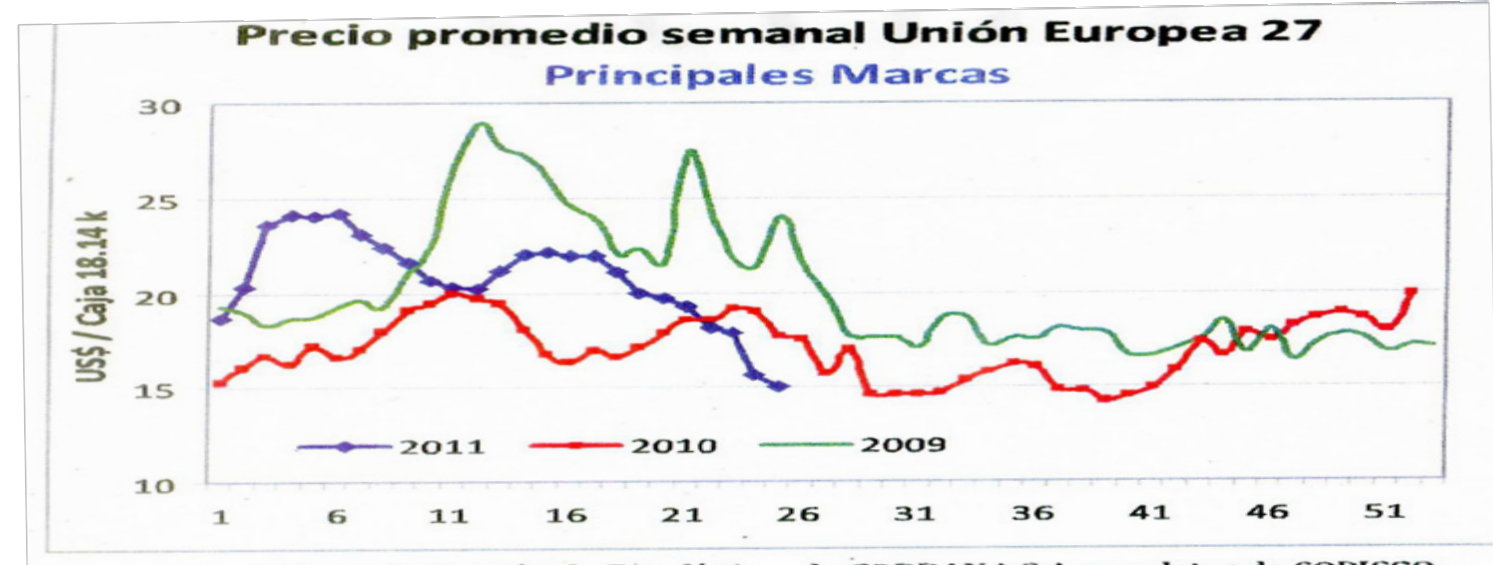

Fuente: Elaborado por la Sección de Estadísticas de CORBANA S.A. con datos de SOPISCO

FIGURA 6: Precio promedio semanal "spot” en E.U 27.

\section{CUADRO 13}

\section{FERTILIZANTES ORGÁNICOS SÓLIDOS REFORZADOS NUTRICIONALY BIOLÓGICA}

\begin{tabular}{|c|c|c|c|c|}
\hline COMPUESTO & CONTENIDO & CANTIDAD & KILOS/ & REDUCCIÓN \\
\hline & $\%$ & Saco de $50 \mathrm{kgrs}$ & HA/AÑO & $\%$ \\
\hline Sulfato de potasio & $50 \% \mathrm{~K} 20$ & 2 & 332 & 66 \\
\hline Sulfato de magnesio & $16 \% \mathrm{MgO}$ & 1 & & \\
\hline Roca fosfórica & 24\% P2O5-46\% CaO & $10 \mathrm{kgrs}$ & & \\
\hline Gallinasas (Harina de soya) & $\mathrm{N}^{11 \%}$ & 2 & 161,42 & 54 \\
\hline Dolomita & $28 \% \mathrm{CaO}-18 \% \mathrm{MgO}$ & 1 & & \\
\hline Sulfato de zinc & $18 \% \mathrm{Zn}$ & 2 kgrs & & \\
\hline Acido bórico & $11-17 \% \mathrm{~B}$ & $2 \mathrm{kgrs}$ & & \\
\hline Compost & Variable & 8 & & \\
\hline $\begin{array}{l}\text { Productos biológicos } \\
\text { ( Bacterias, hongos, etc) }\end{array}$ & \multicolumn{2}{|l|}{ Según fuente } & & \\
\hline
\end{tabular}

APLICAR 0,50 KGRS POR PLANTA CADA 6 SEMANAS 


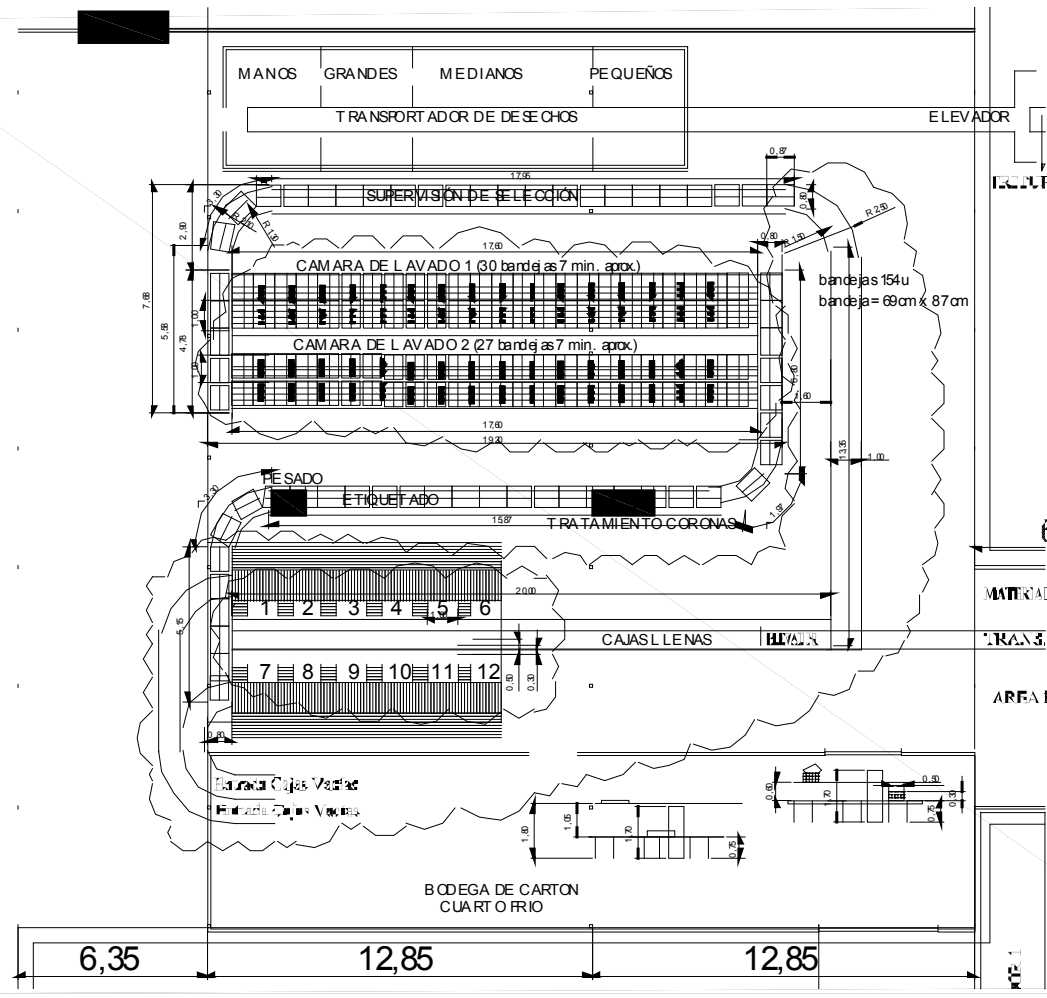

FIGURA 7: Planta de empaque de bandejas móviles.

\section{REFERÊNCIAS}

SOTO, M. Renovación de plantaciones bananeras, um negocio sostenible, mediante el uso de umbrales de produtividad, fijados por agricultura de precisón. Acorbat, Joinville, v. 01, p. 178-179, 2006.
SOTO, M. Nuevas tecnologias sobre desarrolo sostenible em el cultivo del banano. VII SIBANANA, Registro, SP, 2010. 